\title{
Assessing the Quality of Life of Filipino Cancer Patients: A Survey of Filipino Oncologists
} \author{
Jorge Ignacio ${ }^{1} \quad$ Corazon Ngelangel ${ }^{1}$
}

Frederic Ivan Ting ${ }^{1} \quad$ Jose Miguel Callueng ${ }^{2} \quad$ Jeremiah Vallente ${ }^{3}$ Reya Andrea Hurtado ${ }^{4}$ Arjel Ramirez ${ }^{5}$ Lance Isidore Catedral ${ }^{1}$ Rich Ericson King ${ }^{1}$ Rogelio Velasco Jr. ${ }^{1}$ Karen Anjela Mondragon ${ }^{1}$

\begin{abstract}
Address for correspondence Frederic Ivan Ting, MD, Division of Medical Oncology, Department of Medicine, University of the Philippines-Philippine General Hospital, Taft Avenue, Manila 1000, Philippines (e-mail: fredtingmd@gmail.com).
\end{abstract}

\begin{abstract}
Keywords

- clinical practice

- Filipino cancer patients

- oncologists

- quality of life

Introduction Recent trials of new drugs have placed much emphasis on survival. However, several guidelines have emphasized the need for assessing health-related quality of life (HRQoL) as part of the holistic approach in the management of cancer patients. There are currently no national governing guidelines and no existing data on the status of HRQoL assessments by Filipino oncologists, thus this study.

Study Design This was a cross-sectional study that utilized a validated questionnaire. Descriptive and multivariate analyses were used to analyze the data.

Results A total of 312 oncologists participated in this study. Majority were medical oncologists (41\%), followed by radiation oncologists (25\%), hematologists (14\%), gynecologic oncologists (12\%), and surgical oncologists (8\%). About $96 \%$ reported that HRQoL assessment was important for clinical work; however, $58 \%$ perceived HRQoL to be a vague term and $55 \%$ felt they were insufficiently trained to assess HRQoL. About $89 \%$ reported that they will be more confident if local HRQoL assessment guidelines will be present, and $93 \%$ agreed to the use of a unified HRQoL assessment tool for Filipino cancer patients. About $85 \%$ thought that the optimal number of questions for a HRQoL assessment tool should be between 5 and 15 questions. The significant predictors of HRQoL assessment among oncologists were field of oncology and years in practice/training $(p<0.05)$.

Conclusion Filipino oncologists perceived HRQoL patient assessments to be important in clinical practice. However, majority did not know which tool to use and did not feel sufficiently trained to assess HRQoL. The creation of a practice guideline that would facilitate the use of a unified HRQoL assessment tool for Filipino cancer patients is highly recommended.
\end{abstract}

DOI https://doi.org/

$10.1055 / \mathrm{s}-0040-1703420$ ISSN 2454-6798.
(C)2020 Spring Hope Cancer Foundation \& Young Oncologist Group of Asia
License terms

() (1) $\odot \circledast$ 


\section{Introduction}

The World Health Organization (WHO) defines health as "a state of complete physical, mental and social well-being and not merely the absence of disease or infirmity." ${ }^{1}$ This follows that as physicians in charge of the long-term care of patients with cancer, oncologists should not only focus on the survival impact of a patient's treatment regimen but equally important is assessing how the cancer treatment is affecting the different aspects of a patient's life. Quality of life (QoL) is a broad term signifying the present overall well-being of a person that includes not only his emotional, social and physical status but also his/her ability to do activities of daily living.-4

With the incidence of cancer increasing worldwide including the Philippines, ${ }^{5}$ the treatment landscape has advanced into more personalized medicine with the primary end goal of improving survival outcomes. Many oncology groups such as the European Organization for Research and Treatment of Cancer (EORTC), the American Society of Clinical Oncology (ASCO), and the European Society of Medical Oncology (ESMO) have emphasized the need for health-related quality of life (HRQoL) assessment. ${ }^{6,7}$ However, a recently published study in 2018 revealed that despite the palliative intent of treatments in patients with advanced/metastatic cancer, the availability of QoL data remains poor, primarily due to noninclusion of QoL end points in large cancer clinical trials. ${ }^{8}$ Greater inclusion of prespecified QoL measures and improved reporting of QoL outcomes is imperative because it ensures that treatment and evaluations focus on the patient rather than the disease. ${ }^{9}$

In 1997, the University of the Philippines-Department of Health (UP-DOH) QoL scale was created and validated to be a culturally appropriate tool in measuring the HRQoL of Filipino cancer patients. ${ }^{10}$ Unfortunately, there are presently no specific local guidelines to its general use and there are no existing data on the status of HRQoL assessments by Filipino oncologists, which is already considered to be an essential part of the general "wholistic" assessment of cancer patients. ${ }^{11-17}$ Patients may not have treatment benefits in terms of traditional end points, such as overall survival or disease-free survival, but it is still possible to see changes in their QoL. ${ }^{12,18-24}$

This study explored the present status of HRQoL assessment of cancer patients by Filipino oncologists.

\section{Objectives}

This study aimed to evaluate the present status of the Filipino oncologists' approach in assessing the QoL of cancer patients. Specifically, this study:

1. described the attitude of Filipino oncologists on HRQoL assessment;

2. evaluated the implementation of HRQoL assessment by Filipino oncologists in the clinical setting; and

3. identified the different factors that influence the Filipino oncologists' HRQoL assessment of cancer patients in clinical practice.

\section{Materials and Methods}

\section{Study Design and Setting}

After obtaining approval from the University of the Philippines Manila Ethics Review Board, a cross-sectional survey among clinical oncologists and oncologists-in-training, practicing, or training in the Philippines was performed. The HRQoL assessment form, a quantitative and qualitative questionnaire, was used to obtain data, including socio-demographic information, questions on how HRQoL is assessed, the oncologists' general attitude toward the concept of HRQoL, and the different factors that affect HRQoL assessment in clinical practice. Respondents in the study were recruited through email channeled through the specialty societies (e.g., Philippine Society of Medical Oncology, Philippine Society of Radiation Oncology, Philippine Society of Gynecologic Oncology, Philippine Society of Hematology, Philippine Society of Surgical Oncology) after being granted permission from their Head of Office/President. Purposive sampling during specialty conferences or gatherings was also done.

\section{Questionnaire Development}

The questionnaire used was adapted from previous studies obtained from review of literature. ${ }^{12,25-31}$ The instrument consisted of four parts: (1) study introduction and objectives to fully inform the participant what the study is all about; (2) demographic data including age, gender, oncologic specialty, level of training, and working environment; (3) ten closed questions about their attitude toward HRQoL (Likertscales); (4) seven questions regarding their assessment of HRQoL in clinical practice.

Content validity of the questionnaire was evaluated by a panel consisting of five oncology consultants, and five oncologists-in-training. Modifications were made according to their recommendations before subjecting to preliminary testing. ${ }^{32-34}$

Face validity and reliability were assessed by preliminary testing on a convenience sample of 30 oncologists/ oncologists-in-training in the study setting who were excluded from the main study. Respondents were asked for comments on the readability of the items, and for suggestions to make the questions easier to understand, if needed. Participants were asked to accomplish the questionnaire again after 2 weeks to obtain test-retest stability. The survey questions were deemed homogenous, with acceptable internal consistency (Pearson's correlation test-retest coefficient 0.9 , and Cronbach's $\alpha$ reliability coefficient 0.85 ).

Construct validity, the degree to which inferences regarding a theoretical construct can be made based on certain operationalizations, was evaluated using a two-stage sorting procedure consisting of an unstructured followed by a structured sorting exercise. This was used to evaluate for both convergent and discriminant validity, which is important because several items on the questionnaire were self-developed based on the current study objectives. The hit rate was $90 \%$ after the second stage of the sorting procedure and was deemed acceptable. ${ }^{35}$ Validity was further determined through factor analysis, with a minimum factor loading of 0.5 for each item required for all items in the final 
survey questionnaire. Results from the validity and reliability testing were used to determine the final list of questions that were included in the questionnaire.

The final survey consisted of the following three parts:

1. Demographic data (age, gender, field of oncology, level of training, working environment, bulk of cancer type seen in practice);

2. Ten questions about the Filipino oncologists' attitude toward HRQOL assessment;

3. Seven questions regarding the Filipino oncologists' assessment of HRQOL in clinical practice.

\section{Population Selection} Inclusion Criteria

1. Clinical oncologist practicing in the Philippines (medical oncologists, surgical oncologists, gynecologic oncologists, adult hematologists, and radiation oncologists);

2. Clinical oncologist-in-training in the Philippines (medical oncologists, surgical oncologists, gynecologic oncologists, adult hematologists, and radiation oncologists);

3. Clinical oncologists/oncologists-in-training who are registered in their respective societies and who have active email addresses;

4. Clinical oncologists/oncologists-in-training who attended the annual convention of their respective societies.

\section{Exclusion Criteria}

1. Clinical oncologists/oncologists-in-training who are not officially registered in their respective societies;

2. Clinical oncologists/oncologists-in-training who refused to answer the survey.

\section{Clinical and Demographic Characteristics}

Clinical data analyzed included age, gender, field of oncology (medical, surgical, radiologic, gynecologic, hematologic), level of training (consultant or fellow-in-training), working environment (government, private, or both), and bulk of cancer type seen in clinical practice.

\section{Statistical Analysis}

Demographic characteristics were summarized using descriptive statistics (mean and standard deviation). Attitudes and perceptions on HRQoL assessment were described using frequencies and percentages.

Logistic regression analysis was used to determine the statistically significant predictors of use of various means of assessment of QoL. Backward elimination method was the variable selection procedure used in this analysis. A probability to remove of $5 \%$ was used as cutoff in determining variables to be retained in the final model. Both descriptive and inferential statistics were calculated using Stata 14 SE.

\section{Results}

\section{Clinicodemographic Profile}

A total of 312 Filipino oncologists, from five subspecialities, participated in the study (-Table 1 ). The mean age of the oncologists was 38 years old (standard deviation of 7.73 years). Majority were female (63\%), practiced in Luzon (80\%), practicing oncology for an average of 6 years.

Attitude of Filipino Oncologists on HRQoL Assessment Ninety-six percent of the participants reported that HRQoL is important for clinical work (-Table 2). Only $42 \%$ of the oncologists disagree that HRQoL is a vague term and about two-thirds perceived HRQoL as suitable for daily

Table 1 Profile of the Filipino oncologists $(n=312)$

\begin{tabular}{|c|c|c|}
\hline Characteristics & Frequency & Percentage (\%) \\
\hline \multicolumn{3}{|l|}{ Gender } \\
\hline Male & 117 & 37.50 \\
\hline Female & 195 & 62.50 \\
\hline \multicolumn{3}{|l|}{ Location } \\
\hline Luzon & 250 & 80.13 \\
\hline Visayas & 44 & 14.10 \\
\hline Mindanao & 18 & 5.77 \\
\hline \multicolumn{3}{|l|}{ Field of oncology } \\
\hline Medical & 129 & 41.35 \\
\hline Surgical & 24 & 7.69 \\
\hline Radiologic & 78 & 25.00 \\
\hline Gynecologic & 36 & 11.54 \\
\hline Hematology & 45 & 14.42 \\
\hline \multicolumn{3}{|l|}{ Level of training } \\
\hline Consultant & 197 & 63.14 \\
\hline Fellow-in-training & 115 & 36.86 \\
\hline \multicolumn{3}{|l|}{ Working environment } \\
\hline Government & 122 & 39.10 \\
\hline Private & 89 & 28.53 \\
\hline Both & 101 & 32.37 \\
\hline \multicolumn{3}{|l|}{$\begin{array}{l}\text { Bulk of cancer type seen in } \\
\text { practice }\end{array}$} \\
\hline Breast cancer & 224 & 71.79 \\
\hline Colorectal cancer & 135 & 43.27 \\
\hline Head and neck cancer & 130 & 41.67 \\
\hline Cervical cancer & 114 & 36.54 \\
\hline Lymphoma & 98 & 31.41 \\
\hline Lung cancer & 89 & 28.53 \\
\hline Endometrial cancer & 62 & 19.87 \\
\hline Leukemia & 48 & 15.38 \\
\hline Ovarian cancer & 36 & 11.54 \\
\hline Other cancers & 15 & 4.81 \\
\hline Sarcoma & 7 & 2.24 \\
\hline \multirow[t]{2}{*}{ Liver cancer } & 5 & 1.60 \\
\hline & Mean & SD \\
\hline Age (in years) & 38 & 7.73 \\
\hline Years in practice/training & 6 & 5.52 \\
\hline
\end{tabular}

Abbreviation: SD, standard deviation. 




clinical use. Almost all oncologists (97\%) perceived that HRQoL assessment is valuable in patient management. While majority (91\%) of the oncologists perceive that validated HRQoL instruments are useful for QoL assessments, more than two-thirds (69\%) of the oncologists agree that verbal HRQoL assessments are generally enough. Furthermore, $39 \%$ of the oncologists reported that their patients do not accept HRQoL questionnaires and another 39\% of the oncologists were unsure if their patients accept HRQoL questionnaires.

More than three-fourths (78\%) of the oncologists do not know which HRQoL assessment tool to use for Filipino patients, and $78 \%$ of the oncologists perceived that HRQoL questionnaires are too extensive and too lengthy for routine. Lastly, more than half (54\%) of the oncologists reported that they are not sufficiently trained to assess HRQoL.

\section{Implementation of HRQoL Assessment by Filipino Oncologists in the Clinical Setting}

The oncologists reported that the most common motivations for assessment of their patients' QoL were to support a therapy choice (86\%) and for baseline assessment (81\%) (-Table 3).

The most common means of assessment of QoL employed by the participants was interview using nonstandardized queries (-Table 4).

The most commonly reported validated HRQoL questionnaires that oncologists are familiar with and comfortable to use were the Eastern Cooperative Oncology Group (ECOG) score (76\%), and the Karnofsky Index (68\%) (-Table 5).

Majority of the oncologists (89\%) reported that they will be more confident when local HRQoL assessment guidelines are present, and 93\% agreed to the use of a unified HRQoL assessment tool for Filipino cancer patients (- Table 6).

More than half $(58 \%)$ of the oncologists utilized HRQoL assessment for advanced/metastatic cancers, while $39 \%$ used it for both early and advanced stage disease ( - Table 7 ). Most (85\%) oncologists preferred that the optimal number of questions for a HRQoL assessment tool should be between 5 and 15 questions (-Table 8).

\section{Factors Influencing the Filipino oncologists' HRQoL Assessment}

The significant predictors of HRQoL assessment among oncologists were field of oncology and year in practice/training $(p<0.05$, - Table 9). In particular among the fields of oncology, the odds of doing HRQoL assessment were highest among radiation oncologists (6.6 times higher compared with medical oncologists). Meanwhile, the odds of doing HRQoL assessment decreased by $16 \%$ per year increase in the oncologists' years in practice/training.

\section{Discussion}

This study showed that Filipino oncologists perceived HRQoL patient assessments to be important in clinical practice. However, majority did not know which tool to use and did not feel sufficiently trained to assess HRQoL. 
Table 3 Primary motivation for the assessment of your patients' QoL $(n=312)$

\begin{tabular}{|l|l|l|}
\hline Motivation & Frequency & Percentage (\%) \\
\hline To support a therapy choice & 269 & 86 \\
\hline Baseline assessment & 253 & 81 \\
\hline Evaluate follow-up & 244 & 78 \\
\hline For research purposes & 103 & 33 \\
\hline
\end{tabular}

Abbreviation: QoL, quality of life.

Table 4 Means of QoL assessment utilized by respondents $(n=312)$

\begin{tabular}{|l|l|l|}
\hline Means of assessment & Frequency & Percentage (\%) \\
\hline $\begin{array}{l}\text { Verbal/interview using } \\
\text { nonstandardized queries }\end{array}$ & 258 & 83 \\
\hline $\begin{array}{l}\text { Verbal/interview using a } \\
\text { standardized questionnaire }\end{array}$ & 64 & 21 \\
\hline $\begin{array}{l}\text { Combined verbal and written } \\
\text { questionnaire }\end{array}$ & 46 & 15 \\
\hline $\begin{array}{l}\text { Written validated } \\
\text { questionnaire }\end{array}$ & 30 & 10 \\
\hline
\end{tabular}

Abbreviation: QoL, quality of life.

Table 5 Validated HRQoL questionnaire that oncologists perceive to be familiar and comfortable to use $(n=312)$

\begin{tabular}{|l|l|l|}
\hline $\begin{array}{l}\text { Validated HRQoL } \\
\text { Questionnaire }\end{array}$ & Frequency & Percentage (\%) \\
\hline ECOG score & 237 & 75.96 \\
\hline Karnofsky Index & 211 & 67.63 \\
\hline WHO-QoL questionnaire & 82 & 26.28 \\
\hline $\begin{array}{l}\text { EORTC QLQ-C30 } \\
\text { questionnaire }\end{array}$ & 77 & 24.68 \\
\hline UP-DOH QoL assessment tool & 17 & 5.45 \\
\hline None & 24 & 7.69 \\
\hline
\end{tabular}

Abbreviations: ECOG, Eastern Cooperative Oncology Group; EORTC, European Organization for Research and Treatment of Cancer; HRQoL, health-related quality of life; UP-DOH, University of the Philippines-Department of Health; WHO-QoL, World Health Organization Quality of Life.

\section{Attitude of Filipino Oncologists on HRQoL Assessment}

The general positive interest and attitude of Filipino oncologists in assessing HRQoL of their patients are similar to those observed in physicians of other countries. ${ }^{36-39}$

The results of our study also indicated that a recognition of the utility and importance of HRQoL assessment did not necessarily translate to routine use in clinical practice. It is striking to note that there was an overwhelming agreement that HRQoL assessment is important, with two-thirds of the participants indicating its suitability for daily use. However, the participants have been referring to verbal assessments of HRQoL instead of using standardized HRQoL instruments.

From the physician's perspective, it is more convenient to ask random questions instead of having to answer lengthy

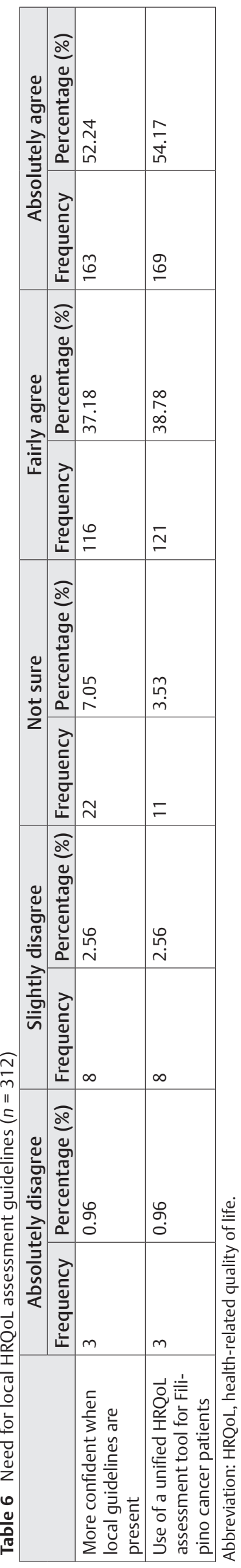


Table 7 Cancer stage wherein respondents conduct HRQoL assessment

\begin{tabular}{|l|l|l|}
\hline Cancer stage & Frequency & Percentage (\%) \\
\hline Early stage cancers & 9 & 3 \\
\hline Advanced/metastatic cancers & 180 & 58 \\
\hline Both & 123 & 39 \\
\hline
\end{tabular}

Abbreviation: HRQoL, health-related quality of life.

Table 8 The optimal number of questions for a HRQoL assessment tool, according to the respondents

\begin{tabular}{|l|l|l|}
\hline $\begin{array}{l}\text { Optimal number } \\
\text { of questions }\end{array}$ & Frequency & Percentage (\%) \\
\hline $5-10$ & 138 & 44 \\
\hline $10-15$ & 126 & 40 \\
\hline $15-20$ & 24 & 8 \\
\hline $20-25$ & 15 & 5 \\
\hline$>25$ & 9 & 3 \\
\hline
\end{tabular}

Abbreviation: HRQoL, health-related quality of life.

Table 9 Significant predictors of use of verbal/interview using nonstandardized queries for HRQoL assessment among oncologists $(n=312)$

\begin{tabular}{|c|l|l|l|l|}
\hline \multirow{2}{*}{ Factors } & \multirow{2}{*}{ Odds ratio } & \multicolumn{2}{|c|}{$95 \% \mathrm{Cl}$} & \multirow{2}{*}{ p-Value } \\
\cline { 3 - 4 } & & $\mathrm{LL}$ & $\mathrm{UL}$ & \\
\hline Field of oncology & & & & \\
\hline Medical & 1.00 & - & - & - \\
\hline Surgical & 1.81 & 0.53 & 6.17 & 0.345 \\
\hline Radiologic & 6.60 & 2.00 & 21.81 & 0.002 \\
\hline Gynecologic & 2.21 & 0.65 & 7.45 & 0.203 \\
\hline Hematology & 0.98 & 0.40 & 2.38 & 0.958 \\
\hline $\begin{array}{l}\text { Years in practice/ } \\
\text { training }\end{array}$ & 0.84 & 0.73 & 0.95 & 0.007 \\
\hline
\end{tabular}

Abbreviations: $\mathrm{Cl}$, confidence interval; $\mathrm{HRQoL}$, health-related quality of life; LL, lower limit; UL, upper limit.

questionnaires that would take too much time. The hesitation to do HRQoL assessment routinely may also be due to the oncologists' perceived notion that the instruments are too extensive and lengthy for routine clinical use. ${ }^{40}$ Interestingly, this perception is not unique to Filipino physicians. ${ }^{41-43}$ Our results also showed that approximately $80 \%$ of the oncologists were either sure that answering HRQoL was unacceptable to their patients or that they were uncertain if it was acceptable at all. The inconvenience that this would cause their patients may have driven the physicians' hesitation in using standardized questionnaires.

It is noteworthy that, aside from the impracticability of using lengthy HRQoL assessment tools in routine clinical practice, several factors exist as to why these tools are not more frequently used. These include uncertainty as to what HRQoL tool to use, as well as a lack of training or orientation in assessing HRQoL of patients. This stresses the importance of continuing medical education, with lectures and symposia dedicated to informing and encouraging oncologists to include HRQoL assessments in clinical practice. Oncologists-in-training may also benefit from the inclusion of HRQoL assessments in their curriculum. Certainly, it is not just Filipino oncologists who feel this way; a study among Dutch physicians showed that they felt they were not sufficiently trained to using HRQoL tools either. ${ }^{36}$

\section{Implementation of HRQoL Assessment by Filipino Oncologists in the Clinical Setting}

HRQoL assessment was used by the majority to support a therapeutic choice, for baseline assessment, and as part of evaluation during follow-up. This result is similar to a study among urologists in Germany, ${ }^{29}$ while interestingly a study done among physicians in Italy mainly obtained HRQoL assessment for research purposes. ${ }^{44}$

Majority assessed the patients' HRQoL verbally using nonstandardized queries. Unfortunately, several studies have already proven that the use of standardized validated instruments for HRQoL assessment is more accurate and reliable in the management of cancer patients. ${ }^{45-51}$

Furthermore, majority of the Filipino oncologists were familiar and comfortable to use the ECOG score and Karnofsky Index as a method of HRQoL assessment. However, studies have shown that more accurate and wholistic tools to use that would cover assessment of the cancer patients' biological/physiological variables, symptom status, and functional status are the WHO-QOL and the EORTC QLQ-C30 questionnaires. ${ }^{52-55}$ In fact, a study done in London suggested that HRQoL information can improve patient care by improving communication between the patient and the physician, prioritizing problems for treatment, screening for unmet needs that may warrant referral to other subspecialties, identifying patient preferences among the goals of treatment that could improve adherence, and monitoring adverse effects of treatment that may not be evident clinically. ${ }^{56}$

Also, only $5 \%$ of the Filipino oncologists know that there is already an existing standardized and validated HRQoL questionnaire specifically for Filipino cancer patients-the UP-DOH QoL assessment tool crafted by Ngelangel in $2008 .^{2}$

Majority of the Filipino oncologists agreed to the use of a unified HRQoL assessment tool for Filipino cancer patients and that they would be more confident if local guidelines for its use are present. Moreover, majority reported that the optimal number of questions in the assessment tool should be between 5 and 15 for it to be practical for daily use. These results are consistent with the findings in several studies that indicate the importance of national guidelines in the use of HRQoL assessment tools especially in encouraging physicians to incorporate it in their daily practice. ${ }^{57-61}$

Also, one of the lessons learned during the creation of the EORTC QOL questionnaire used universally in European countries is that the length of the questionnaire should not only be complete enough to cover the different aspects of the patients' QoL, but of equal importance is that its length and administration time should also be well accepted by the physicians for its use to be successful. ${ }^{62-64}$ 


\section{Factors Influencing the Filipino Oncologists' HRQoL Assessment}

Factors noted to significantly influence doing HRQoL assessment among Filipino oncologists were field of oncology and years in practice/training.

As the seniority of the oncologists increases whether in practice or in fellowship training, their use decreases by $16 \%$ per year. This might be explained by a finding in one study done in Canada which showed that $69 \%$ of the respondents (mostly $>50$ years old) would be more likely to base their treatment recommendations on personal experience rather than on published QOL literature. ${ }^{65-67}$ Furthermore, this trend could be further explained by the fact that the value of these standardized tools has been questioned by some older clinicians who feel they are able to derive the same information by simply talking to the patients in a less structured way in their clinical practice. ${ }^{68,69}$ These results are in contrast to the findings of a study done in Italy which showed that knowledge and use of the HRQoL standardized assessment tools are independent of age, gender, and medical specialty. ${ }^{44}$

Interestingly, radiation oncologists were more likely to assess HRQoL. The reason for this may possibly be because radiation oncologists see the patients more frequently while they are having their radiation treatment and the effect of always asking how the patients are-bringing the patients' concerns and symptoms to the physicians' attention. ${ }^{70,71}$

\section{Clinical Implications}

The findings of this study are very important and can be considered an eye opener to Filipino oncologists. This study showed that although $96 \%$ of the respondents reported that HRQoL assessment is important for their clinical work, majority do so verbally using nonstandardized open questions (e.g., How are you?). While this may be of relative benefit to the clinicians, this method of assessment may lead to failure of assessing the full spectrum of HRQoL..$^{72-74}$ Another important point that Filipino oncologists should realize is that similar to a previous study, physicians sometimes underestimate the impact of the patients' disease on their HRQoL and therefore should be evaluated using standardized tools. ${ }^{75}$

\section{Limitations}

This study had a $40 \%$ response rate from Filipino oncologists $312 / 771$. The unequal small sample distribution among the different oncologic subspecialties remains the major limitation of this study probably due to the poor response rate from some oncologic subspecialties.

\section{Conclusion}

Filipino oncologists perceived HRQoL patient assessments to be important in clinical practice. However, majority did not know which tool to use and did not feel sufficiently trained to assess HRQoL. The creation of a practice guideline that would facilitate the use of a unified HRQoL assessment tool (containing 5-15 questions) for Filipino cancer patients is highly recommended.

\section{Recommendations}

The data gathered can hopefully be used to develop national guidelines reinforcing the regular use and application of HRQoL assessments, thereby facilitating the best possible quality of care that can be given to our cancer patients.

Further studies can also be done to identify training needs and educational reinforcements for oncologists as it has been deemed necessary by the results of this study.

An exploratory study is recommended to investigate the reasons why some Filipino cancer patients do not accept using HRQoL questionnaires in clinical practice. Once the reasons are identified, then the Filipino oncologists would be better equipped to address this barrier.

Also, the creation of a unified HRQoL assessment tool (containing 5-15 questions) for Filipino cancer patients is highly recommended.

\section{Note}

All authors equally contributed in this study and in the preparation of the manuscript.

\section{Conflict of Interest}

None declared.

\section{Acknowledgments}

The authors are indebted to all members of the UP-PGH Research Committee of the Department of Medicine and Divisions of Medical Oncology, Radiation Oncology, Hematology, Gynecologic Oncology, and Surgical Oncology. Likewise, the authors would like to extend their utmost gratitude to the Philippine Society of Medical Oncology, Philippine Radiation Oncology Society, Philippine College of Hematology and Transfusion Medicine, Society of Gynecologic Oncologists of the Philippines, and the Surgical Oncology Society of the Philippines for their support in this endeavor. The authors especially thank Ms. Kim Cochon for her statistical expertise.

\section{References}

1 World Health Organization. Preamble to the Constitution of the World Health Organization as adopted by the International Health Conference, New York, 19 June-22 July 1946. Available at: http://whqlibdoc.who.int/hist/official_records/ constitution.pdf. Accessed February 10, 2020

2 Ngelangel CA. Quality of life of Filipino cancer patients. Asia Pac J Oncol Haematol 2008;1(1):18-19

3 Knobel H, Håvard Loge J, Lund MB, Forfang K, Nome O, Kaasa S. Late medical complications and fatigue in Hodgkin's disease survivors. J Clin Oncol 2001;19(13):3226-3233

4 Bezjak A, Ng P, Skeel R, Depetrillo AD, Comis R, Taylor KM. Oncologists' use of quality of life information: results of a survey of Eastern Cooperative Oncology Group physicians. Qual Life Res 2001;10(1):1-13

5 Laudico AV, Mirasol-Lumague MR, Medina V, Mapua CA, Valenzuela FG, Pukkala E. Philippine Cancer Facts and Estimates 2015. Philippine Cancer Society 2015. Available at: http://www.philcancer.org.ph/wp-content/uploads/2017/07/2015-PCS-Ca-FactsEstimates_CAN090516.pdf. Accessed February 10, 2020 
6 EORTC. Quality of Life Department. Available at: https://www. eortc.org/research_field/quality-of-life/. Accessed February 13,2020

7 ESMO. Available at: http://esmo.org. Accessed February 13, 2020

8 Gyawali B, Hwang T. Prevalence of quality of life (QoL) outcomes and association with survival in cancer clinical trials. J Clin Oncol 2018;36(Suppl):6573

9 Higginson IJ, Carr AJ. Measuring quality of life: using quality of life measures in the clinical setting. BMJ 2001;322(7297):1297-1300

10 Ramiro LS, Ngelangel CA, Amarillo ML. The UP-DOH QOL scale: measures of quality of life of Filipino cancer patients. Philipp J Intern Med 1997;(July-August):179-188

11 Chang VT, Thaler HT, Polyak TA, Kornblith AB, Lepore JM, Portenoy RK. Quality of life and survival: the role of multidimensional symptom assessment. Cancer 1998;83(1):173-179

12 Bottomley A. The cancer patient and quality of life. Oncologist 2002;7(2):120-125

13 Spilker B, Ed. Quality of Life and Pharmacoeconomics in Clinical Trials. 2nd edition. New York: Raven Press; 1996: 1-10

14 Varricchio CG, McCabe MS, Trimble E, Korn EL. Quality of life in clinical cancer trials. Introduction. J Natl Cancer Inst Monogr 1996;20(20):vii-viii

15 Osoba D. Lessons learned from measuring health-related quality of life in oncology. J Clin Oncol 1994;12(3):608-616

16 Feld R. Endpoints in cancer clinical trials: is there a need for measuring quality of life? Support Care Cancer 1995;3(1):23-27

17 Stephens RJ, Hopwood P, Girling DJ, Machin D. Randomized trials with quality of life endpoints: are doctors' ratings of patients' physical symptoms interchangeable with patients' self-ratings? Qual Life Res 1997;6(3):225-236

18 Titzer ML, Fisch M, Kristellar JL, et al. Clinician's assessment of quality of life (QOL) in outpatients with advanced cancer: how accurate is our prediction? A Hoosier oncology study. Am Soc Clin Oncol 2001;20:384a

19 Green SB. Does assessment of quality of life in comparative cancer trials make a difference? A discussion. Control Clin Trials 1997;18(4):306-310

20 Kong SX, Gandhi SK. Methodologic assessments of quality of life measures in clinical trials. Ann Pharmacother 1997;31(7-8):830-836

21 Smith KW, Avis NE, Assmann SF. Distinguishing between quality of life and health status in quality of life research: a meta-analysis. Qual Life Res 1999;8(5):447-459

22 Juniper EF, Guyatt GH, Willan A, Griffith LE. Determining a minimal important change in a disease-specific Quality of Life Questionnaire. J Clin Epidemiol 1994;47(1):81-87

23 Osoba D, Rodrigues G, Myles J, Zee B, Pater J. Interpreting the significance of changes in health-related quality-of-life scores. J Clin Oncol 1998;16(1):139-144

24 Kramer JA, Curran D, Piccart M, et al. Identification and interpretation of clinical and quality of life prognostic factors for survival and response to treatment in firstline chemotherapy in advanced breast cancer. Eur J Cancer 2000;36(12):1498-1506

25 Staquet M, Berzon R, Osoba D, Machin D. Guidelines for reporting results of quality of life assessments in clinical trials. Qual Life Res 1996;5(5):496-502

26 van Knippenberg FC, de Haes JC. Measuring the quality of life of cancer patients: psychometric properties of instruments. J Clin Epidemiol 1988;41(11):1043-1053

27 Schumacher M, Olschewski M, Schulgen G. Assessment of quality of life in clinical trials. Stat Med 1991;10(12):1915-1930
28 WHOQOL. Group. Study protocol for the World Health Organization project to develop a Quality of Life assessment instrument (WHOQOL) Qual Life Res 1993;2(2):153-159

29 Schmick A, Juergensen M, Rohde V, Katalinic A, Waldmann A. Assessing health-related quality of life in urology - a survey of 4500 German urologists. BMC Urol 2017;17(1):46-58

30 Donnelly S. Quality-of-life assessment in advanced cancer. Curr Oncol Rep 2000;2(4):338-342

31 Jacobsen PB, Davis K, Cella D. Assessing quality of life in research and clinical practice. Oncology (Williston Park) 2002;16(9, Suppl 10) :133-139

32 Rattray J, Jones MC. Essential elements of questionnaire design and development. J Clin Nurs 2007;16(2):234-243

33 Marsden PV, Writh JD, Handbook of Survey Research. 2nd edition. Connecticut: Emerald Books; 2010

34 Philippine Health Ethics Research Board. National Ethical Guidelines for Health and Health-related Research 2017. Taguig City, Philippines 2017. Available at: http://www.ethics.healthresearch.ph/index.php/phoca-downloads/category/4-neg. Accessed February 10, 2020

35 AgarwalNK. Verifying survey items for construct validity: a two-stage sorting procedure for questionnaire design in information behaviour research (annual meeting conference proceedings). Association for Information Science and Technology, 2011. Available at: https://asistdl.onlinelibrary.wiley.com/doi/ epdf/10.1002/meet.2011.14504801166. Accessed February 10,2020

36 Baars RM, van der Pal SM, Koopman HM, Wit JM. Clinicians' perspective on quality of life assessment in paediatric clinical practice. Acta Paediatr 2004;93(10):1356-1362

37 Skevington SM, Day R, Chisholm A, Trueman P. How much do doctors use quality of life information in primary care? Testing the trans-theoretical model of behaviour change. Qual Life Res 2005;14(4):911-922

38 Velikova G, Awad N, Coles-Gale R, Wright EP, Brown JM, Selby PJ. The clinical value of quality of life assessment in oncology practice-a qualitative study of patient and physician views. Psychooncology 2008;17(7):690-698

39 Velikova G, Booth L, Smith AB, et al. Measuring quality of life in routine oncology practice improves communication and patient well-being: a randomized controlled trial. J Clin Oncol 2004;22(4):714-724

40 Straus SE, Sackett DL. Using research findings in clinical practice. BMJ 1998;317(7154):339-342

41 Osoba D. Health-related quality of life and cancer clinical trials. Ther Adv Med Oncol 2011;3(2):57-71

42 Morris J, Perez D, McNoe B. The use of quality of life data in clinical practice. Qual Life Res 1998;7(1):85-91

43 Young T, Maher J. Collecting quality of life data in EORTC clinical trials-what happens in practice? Psychooncology 1999;8(3):260-263

44 Bossola M, Murri R, Onder G, Turriziani A, Fantoni M, Padua L. Physicians' knowledge of health-related quality of life and perception of its importance in daily clinical practice. Health Qual Life Outcomes 2010;8:43-50

45 MAPI Research Institute. Quality of Life Assessment in Medicine. Available at: http://www.QLMed.org/index.html. Accessed February 2, 2020

46 Endicott J, Nee J, Harrison W, Blumenthal R. Quality of life enjoyment and satisfaction questionnaire: a new measure. Psychopharmacol Bull 1993;29(2):321-326

47 Sigurdardóttir V, Bolund C, Sullivan M. Quality of life evaluation by the EORTC questionnaire technique in patients with generalized malignant melanoma on chemotherapy. Acta Oncol 1996;35(2):149-158 
48 Sigurdardóttir V, Brandberg Y, Sullivan M. Criterion-based validation of the EORTC QLQ-C36 in advanced melanoma: the CIPS questionnaire and proxy raters. Qual Life Res 1996;5(3):375-386

49 Cella DF, Tulsky DS, Gray G, et al. The functional assessment of cancer therapy scale: development and validation of the general measure. J Clin Oncol 1993;11(3):570-579

50 Kemmler G, Holzner B, Kopp M, et al. Comparison of two quality-of-life instruments for cancer patients: the functional assessment of cancer therapy-general and the European Organization for Research and Treatment of Cancer Quality of Life Questionnaire-C30. J Clin Oncol 1999;17(9):2932-2940

51 Bjordal K, Hammerlid E, Ahlner-Elmqvist M, et al. Quality of life in head and neck cancer patients: validation of the European Organization for Research and Treatment of Cancer Quality of Life Questionnaire-H\&N35. J Clin Oncol 1999;17(3):1008-1019

52 Cella DF, Tulsky DS, Gray G, et al. The Functional Assessment of Cancer Therapy scale: development and validation of the general measure. J Clin Oncol 1993;11(3):570-579

53 Cella DF, Bonomi AE, Lloyd SR, Tulsky DS, Kaplan E, Bonomi P. Reliability and validity of the Functional Assessment of Cancer Therapy-Lung (FACT-L) quality of life instrument. Lung Cancer 1995;12(3):199-220

54 Aaronson NK, Ahmedzai S, Bergman B, et al. The European Organization for Research and Treatment of Cancer QLQ-C30: a quality-of-life instrument for use in international clinical trials in oncology. J Natl Cancer Inst 1993;85(5):365-376

55 Aaronson NK, Cull AM, Kaasa S, Sprangers MAG, The European Organization for Research and Treatment of Cancer (EORTC) modular approach for quality of life assessment in oncology: an update. In: Spilker B, ed. Quality of Life and Pharmacoeconomics in Clinical Trials. 2nd edition. Philadelphia: Lippincott-Raven; 1996 179-189

56 Higginson IJ, Carr AJ, The clinical utility of quality of life measures. In: Carr AJ, Higginson IJ, Robinson PG, eds. Quality of Life. BMJ Books: London; 2003 63-78

57 Coates A, Porzsolt F, Osoba D. Quality of life in oncology practice: prognostic value of EORTC QLQ-C30 scores in patients with advanced malignancy. Eur J Cancer 1997;33(7):1025-1030

58 Efficace F, Bottomley A, Coens C, et al. Does a patient's self-reported health-related quality of life predict survival beyond key biomedical data in advanced colorectal cancer? Eur J Cancer 2006;42(1):42-49

59 Gotay CC, Kawamoto CT, Bottomley A, Efficace F. The prognostic significance of patient-reported outcomes in cancer clinical trials. J Clin Oncol 2008;26(8):1355-1363

60 Ediebah DE, Coens C, Zikos E, et al. Does change in health-related quality of life score predict survival? Analysis of EORTC 08975 lung cancer trial. Br J Cancer 2014;110(10):2427-2433

61 Quinten C, Coens C, Mauer M, et al; EORTC Clinical Groups. Baseline quality of life as a prognostic indicator of survival: a meta-analysis of individual patient data from EORTC clinical trials. Lancet Oncol 2009;10(9):865-871

62 Quinten C, Martinelli F, Coens C, et al; Patient Reported Outcomes and Behavioral Evidence (PROBE) and the European Organization for Research and Treatment of Cancer (EORTC)
Clinical Groups. A global analysis of multitrial data investigating quality of life and symptoms as prognostic factors for survival in different tumor sites. Cancer 2014;120(2):302-311

63 van Nieuwenhuizen AJ, Buffart LM, Brug J, Leemans CR, Verdonck-de Leeuw IM. The association between health related quality of life and survival in patients with head and neck cancer: a systematic review. Oral Oncol 2015;51(1):1-11

64 Johnson C, Aaronson N, Blazeby JM, et al. Guidelines for developing Quality of Life Questionnaires. http://groups.eortc.be/ qol/sites/default/files/archives/guidelines_for_developing questionnaire-_final.pdf. Brussels: EORTC Publications; 2011. Accessed May 26, 2015

65 Ediebah DE, Coens C, Maringwa JT, et al; Gastro-Intestinal Tract Cancer Cooperative Group; Lung Cancer Cooperative Group; Quality of Life Department and Patient Reported Outcome and Behavioural Evidence (PROBE). Effect of completion-time windows in the analysis of health-related quality of life outcomes in cancer patients. Ann Oncol 2013;24(1):231-237

66 Pater J, Osoba D, Zee B, et al. Effects of altering the time of administration and the time frame of quality of life assessments in clinical trials: an example using the EORTC QLQ-C30 in a large anti-emetic trial. Qual Life Res 1998;7(3):273-278

67 Bezjak A, Taylor KM, Ng P, Macdonald K, DePetrillo AD. Quality-of-life information and clinical practice: the oncologist's perspective. Cancer Prev Control 1998;2(5):230-235

68 McLachlan SA, Allenby A, Matthews J, et al. Randomized trial of coordinated psychosocial interventions based on patient self-assessments versus standard care to improve the psychosocial functioning of patients with cancer. J Clin Oncol 2001;19(21):4117-4125

69 Velikova G, Wright P, Smith AB, et al. Self-reported quality of life of individual cancer patients: concordance of results with disease course and medical records. J Clin Oncol 2001;19(7):2064-2073

70 Goyal U, Ong S, Cheung MK, et al. Assessment of symptom burden and quality of life in radiation oncology patients. Int J Radiat Oncol Biol Phys 2015;93(3):E491

71 Scott CB, Stetz J, Bruner DW, Wasserman TH. Radiation Therapy Oncology Group quality of life assessment: design, analysis, and data management issues. Qual Life Res 1994;3(3):199-206

72 Institute of Medicine (US) Council on Health Care Technology; Mosteller F, Falotico-Taylor J, eds. Quality of Life and Technology Assessment: Monograph of the Council on Health Care Technology. Washington (DC): National Academies Press (US); 1989

73 Rodriguez KL, Bayliss N, Alexander SC, et al. How oncologists and their patients with advanced cancer communicate about health-related quality of life. Psychooncology 2010;19(5):490-499

74 O'leary MP. Validity of the "bother score" in the evaluation and treatment of symptomatic benign prostatic hyperplasia. Rev Urol 2005;7(1):1-10

75 Litwin MS, Lubeck DP, Henning JM, Carroll PR. Differences in urologist and patient assessments of health related quality of life in men with prostate cancer: results of the CaPSURE database. J Urol 1998;159(6):1988-1992 